\title{
Effect of subreinforcing intracranial stimulation on extinction'
}

\author{
JOSEPH P. HUSTON AND BENJAMIN J. PRESSMAN \\ TUFTS UNIVERSITY
}

Response-contingent intracranial stimulation at pulse-train durations thought to be subreinforcing was presented during extinction to rats. No evidence was found that subreinforcing stimulation would increase resistance to extinction. However. individual records indicated that such stimulation might prolong responding by summation. The pulse-train duration which would no longer maintain responding was found to be between .03 and $.01 \mathrm{sec}$.

Subreinforcing electrical brain stimulation has been studied by Deutsch, Howarth, Ball \& Deutsch (1962) who reported that intracranial stimulation at about one-half threshold intensity can provide resistance to extinction when randomly presented during the extinction session. This was taken as evidence for the drive inducing properties of the stimulation in accord with Deutsch's drive-decay hypothesis of intracranial self-stimulation. Huston (1968) gradually reduced pulsetrain duration to zero as a procedure for establishing fixed ratio performance directly from a continuous reinforcement schedule (CRF). Furthermore, when subreinforcing stimulation, i.e., stimulation of inadequate duration to maintain responding under a CRF schedule, was made contingent on all responses under a fixed-ratio schedule, rate of responding increased, suggesting that the subreinforcing stimulation had mediational properties.

There are a number of possible interpretations regarding the effects of subreinforcing intracranial stimulation. For instance, such stimulation might act as: (a) a drive inducer as Deutsch suggested, (b) a discriminative stimulus or conditioned reinforcer through association with reinforcing stimulation, or (c) a reinforcer through summation effects.

To investigate more thoroughly the effects of subreinforcing stimulation, an experiment was performed to see if response-contingent, short-duration pulse trains would increase resistance to extinction.

Method

Male rats of the Long-Evans strain were implanted with bipolar electrodes. The coordinates used were those reported by Bogacz and Olds (1965) to lie in the anterior lateral hypothalamus and were histologically confirmed in a previously implanted batch of rats. Six positive animals were each allowed about 3000 reinforced responses in a Skinner box with $1000 \mathrm{~Hz}$, ac, square wave, intracranial stimulation. Pulse-train duration was set at $0.5 \mathrm{sec}$, and the current level was 300 microampere, base to peak, for all animals (this current level was used throughout the remainder of the experiment).

After preliminary training, each animal underwent six extinction sessions over six days. Each day, stimulation of a different pulse-train duration was made contingent upon responses during the extinction period. Pulse-train durations were chosen to be $.07, .05$, $.03, .005$, and $0.0 \mathrm{sec}$. These values were thought to be subreinforcing on the basis of pilot work with other animals. The order in which each $\mathrm{S}$ received the different durations, as well as the running order of the Ss each day were determined by means of randomized Latin squares. The extinction procedure on each day consisted of the following steps: (a) 300 acquisition responses at a pulse-train duration of 0.5 sec; (b) a 15 min extinction period during which barpressing produced stimulation at one of the above listed pulse-train durations; (c) 50 acquisition responses with pulse-train duration again at $0.5 \mathrm{sec}$.

A cumulative recorder was used to monitor responses, and an oscilloscope to monitor stimulation parameters.

After the experiment, the records of each $\mathrm{S}$ were examined to determine the apparentduration thresholds for extinction. The Ss were then run at these levels for a $1 \mathrm{~h}$ extinction period. If a $\mathrm{S}$ did not extinguish at the chosen level, he was run again at the next lower level.

\section{Results and Discussion}

The response measure was the number of responses emitted during the $15 \mathrm{~min}$ extinction period. The means for number of responses to extinction at each of the six pulse-train durations are given in Table $1 . \mathrm{Be}-$ cause of heterogeneity of variance, the raw data were transformed into common logs. A repeated-measures analysis of variance proved significant $(p<.01)$. A Newman-Keuls test for differences between individual means (Winer, 1962) showed that the means of the $.07, .05$, and .03 sec treatments were significantly different from these of the $.01, .005$, and $0.0 \mathrm{sec}$ treatments $(p<.05)$, but no other differences were significant.

Table 1.

Mean $(\mathbf{N}=6)$ Number of Responses Emitted During Extinction.

$\begin{array}{lcccccc}\text { Pulse-train duration }(\mathrm{sec}) & .07 & .05 & .03 & .01 & .005 & 0.0 \\ \text { Responses emitted } & 875.7 & 742.8 & 459.0 & 124.8 & 102.2 & 84.5\end{array}$


In the hour-long extinction periods following the actual experiment, two of the Ss definitely extinguished at the .03 sec duration level, while three others extinguished at the $.01 \mathrm{sec}$ level. (One $\mathrm{S}$ could not be tested due to electrode damage.) This result, in combination with the relatively high rates of responding sustained by stimulation at the three longest pulse-train durations, indicates that stimulation at these levels was not subreinforcing. Hence, the significant results of the comparisons of means only shows the difference between acquisition and extinction trials.

Since stimulation at the .07 and .05 levels was definitely not subreinforcing, a repeated-measures analysis of variance was also performed on the transformed data for only the $.03, .01, .005$, and $0.0 \mathrm{sec}$ treatments and was significant $(p<.01)$. Dunnet's tstatistic was applied in order to compare all means with the control mean. Only the $.03 \mathrm{sec}$ treatment was significantly different from the 0.0 sec treatment. However, since the .03 level was not subthreshold for all $\mathrm{Ss}$, this result again provides no confirming evidence for the hypothesis that subreinforcing stimulation of short, pulse-train duration would provide resistance to extinction. It is possible that the longer pulse-train durations used were originally subreinforcing, but acquired reinforcing properties after Ss had extensive experience with reinforcing brain stimulation. Such an interpretation is in accord with the

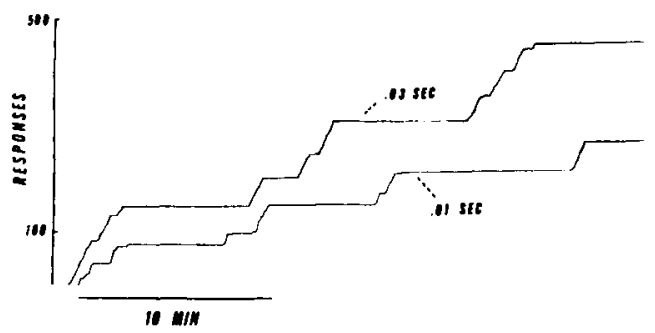

Fig. 1. Cumulative records of two Ss under .03 and $.01 \mathrm{sec}$ pulsetrain durations. findings of Smith \& Cox (1967) that rate of responding under .05 sec duration stimulation gradualiy increased over days of training.

Figure 1 shows portions of the 1 h extinction records of two Ss at duration levels .03 and $.01 \mathrm{sec}$ which eventually led to extinction. Responding tended to occur in bursts at a relatively high rate, with no responding in between. Such bursts followed by long pauses were common in other extinction records. This suggests that short-duration stimuli may have maintained responding by summation, thus resulting in an artifact in the data. This possibility might have been prevented by putting constraints on the maximum rate of successive stimulations. However, a possible summation effect is interesting on its own right, as an explanation for performance under short pulsetrain durations.

Two previous studies on the effects of train duration on rate of responding used $.05 \mathrm{sec}$ as the lowest duration (McIntire \& Wright, 1965; Smith \& Cox, 1967). The present experiment provides an estimate of the pulse-train duration below which responding will not be maintained: in the interval between .03 and .01 sec.

\section{References}

BOGACZ, J., ST. LAURENT, J., \& OLDS, J. Dissaciation of self-stimulation and epileptiform activity. EEG clin. Neurophysiol., 1965, 19, $75-87$.

DEUTSCH, J. A., HOWARTH, C. E., BALL, G. C., \& DEUTSCH, D. Threshold differentiation of drive and reward in the Olds effect. Nature, 1962, 196, 699-700.

HUSTON, J. P. Reinforcement reduction: A method for training ratio behavior. Science, 1968, 159, 444.

McINTIRE, R. W., \& WRIGHT, J. E. Parameters related to response rate for septal and medial forebrain bundle stimulation. J. comp. physiol. Psychol, 1965, 59, 131-134.

SMITH, R. G., \& COX, V. C. Short train durations and self-stimulation rates in the rat. J. comp. physiol. Psychol,, 1967, 64, 513-515.

WINER, B. J. Statistical principles in experimental design. New York: McGraw-Hill, 1962.

Note

1. We are grateful to A. William Mills for his support. 